\title{
Computer Distance Virtual Experiment Teaching Application Based on Virtual Reality Technology
}

\author{
https://doi.org/10.3991/ijet.v13i04.8472 \\ Fengxu Wang \\ Liaocheng University, Liaocheng, China \\ wangfengxu@lcu.edu.cn
}

\begin{abstract}
The rapid development of computer and network has promoted the emergence and development of new teaching methods and teaching media. This paper takes the computer distance virtual experiment teaching as the research goal, by literature investigation, summarization and case analysis methods, basing on analysis of computer distance teaching, Virtual Reality (VR) technology, virtual experiment teaching, and other related technology theories, the paper proposes a computer distance virtual experiment teaching mode based on VR technology. By taking the virtual computer assembly experiment as an example, this paper designs a computer distance virtual experiment teaching mode based on VR technology, realizes the computer distance virtual experiment teaching of the computer assembly experiment, and verifies the feasibility of the teaching mode. The research results indicate that, this teaching mode has a certain practical significance on improving the computer distance teaching mode and promoting the smooth development of computer distance teaching.
\end{abstract}

Keywords-Computer distance teaching; virtual reality (VR) technology; VRML; virtual experiment

\section{Introduction}

Experimental teaching is an important part of the teaching process. Although with the development of computer and network, distance teaching has provided a lot of learning resources for the students, it is limited to theoretical teaching, and making experimental teaching a weak link in the distance teaching [1].

Virtual experiment was developing from the computer network technology and VR technology, it can improve the teaching method of the computer distance teaching. Current foreign virtual laboratories of the VR technology have been widely used in various fields, and obtained great attention and support from the government. Figure 1 shows the Howard Hughes Institute of Medicine Virtual Immunology Laboratory. In our country, many colleges and universities also set up corresponding virtual laboratories according to their own needs. Among these laboratories, University of Science and Technology of China (USTC) is the best in establishing virtual laboratories using VR technologies. Figure 2 shows the buckyball molecule diagram of the college physics virtual experiment distance teaching system developed by USTC. 
Although some achievements have been made in the research of virtual laboratory construction and computer distance virtual experiment teaching based on the VR technology both at home and abroad, there are other issues need to be addressed, such as limited means of online virtual experiment interaction, the to-be- strengthened virtual experiment supporting services, too few studies on virtual experiment theories, limited virtual experiment amount, etc. [2].

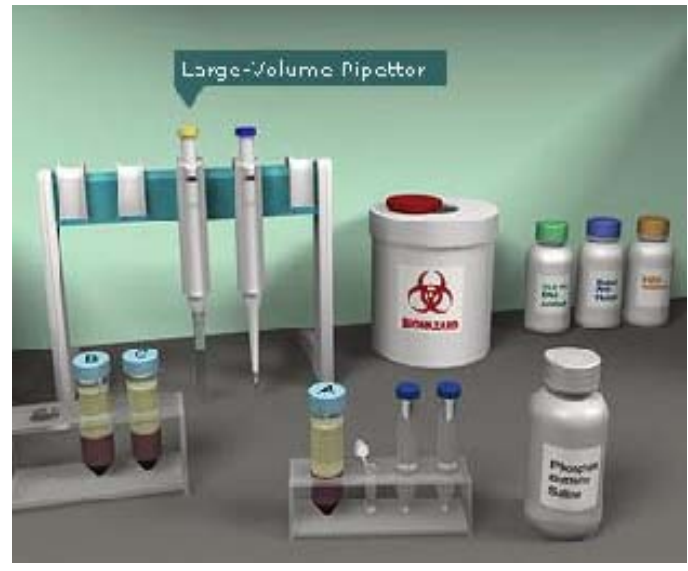

Fig. 1. Virtual immunology laboratory

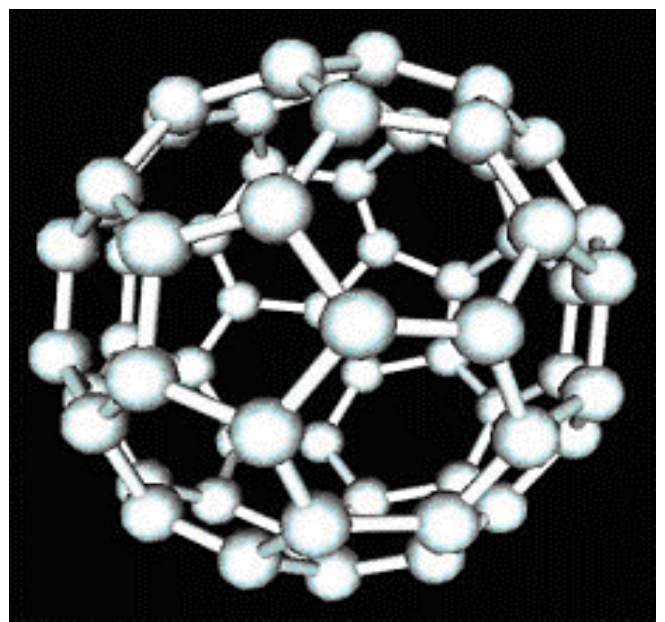

Fig. 2. Buckyball molecule diagram

From above analysis, we can see how to realize the interaction between learners in the distance teaching virtual experiment environment, and the related studies of learning theory [3] are relatively weak. Based on this, this paper carries out study on VR technology-based computer distance virtual experiment teaching related theory and its interaction realization, proposes VR technology-based computer distance vir- 
tual experiment teaching methods, and conducts detail design of it, at last, it verifies the feasibility of this teaching mode by computer assembly experiment.

This paper focuses on the application of computer distance virtual experiment teaching based on the VR technology. The paper is divided into four parts: The first part introduces the research background of computer distance virtual experiment teaching, the current research situation at home and abroad and the existing problems, the main research content and purpose. The second part mainly introduces the related theory of computer distance virtual experiment teaching based on VR technology, including computer distance teaching, VR technology and VRML, virtual experiment and virtual experiment teaching, which lays a theoretical foundation for the next chapter of virtual experiment teaching design. The third part takes the computer assembly experiment as an example. Through the detailed design and implementation of the computer distance experiment teaching, the feasibility of this computer virtual experiment teaching mode based on the VR technology is verified. The fourth part summarizes and prospects the research results of this paper.

\section{VR technology-based computer distance virtual experiment teaching}

\subsection{Computer distance teaching}

Table 1. Development of distance teaching

\begin{tabular}{|l|l|l|c|}
\hline \multicolumn{1}{|c|}{ Name } & \multicolumn{1}{|c|}{ The means of realization } & Information tools & Interactivity \\
\hline $\begin{array}{l}\text { Broadcast correspondence } \\
\text { education }\end{array}$ & $\begin{array}{l}\text { Wired, wireless radio networks, radio } \\
\text { equipment }\end{array}$ & Sound & No \\
\hline $\begin{array}{l}\text { Radio and television edu- } \\
\text { cation }\end{array}$ & $\begin{array}{l}\text { Wired, wireless radio networks, televi- } \\
\text { sion reception equipment }\end{array}$ & $\begin{array}{l}\text { Sound, graphics, } \\
\text { images, text }\end{array}$ & No \\
\hline $\begin{array}{l}\text { Computer Remote Educa- } \\
\text { tion }\end{array}$ & $\begin{array}{l}\text { Computer Internet, multimedia comput- } \\
\text { er }\end{array}$ & $\begin{array}{l}\text { Sound, graphics, } \\
\text { images, text }\end{array}$ & Yes \\
\hline
\end{tabular}

Computer distance teaching came into being with the development of computer, network technology and multimedia technology, it can achieve the teaching information transmission beyond time and space [4], and it is extremely convenient for learners to study and overcomes some disadvantages of the traditional teaching method, thus will become an important means of lifelong learning for the people. The development of computer distance teaching so far has gone through three stages: Broadcast correspondence teaching, Radio and television teaching, Computer distance teaching. Table 1 shows the development of computer distance teaching in three stages [5].

\subsection{VR Technology and VRML}

VR technology. Virtual Reality (VR) is a three-dimensional, interactive, seemingly realistic, simulated real-world environment constructed by computer and electronic 
technologies. People can access to the virtual environment through computer interface and conduct related operations on advanced user interface. Interactivity, immersion and imagine are the three characters [6], as shown in Figure 3, which are also the key features that distinguish VR from other technologies. According to the degree of immersion, VR technology can be divided into four types of VR systems: desktop, distributed, immersive and distance sensing [7].

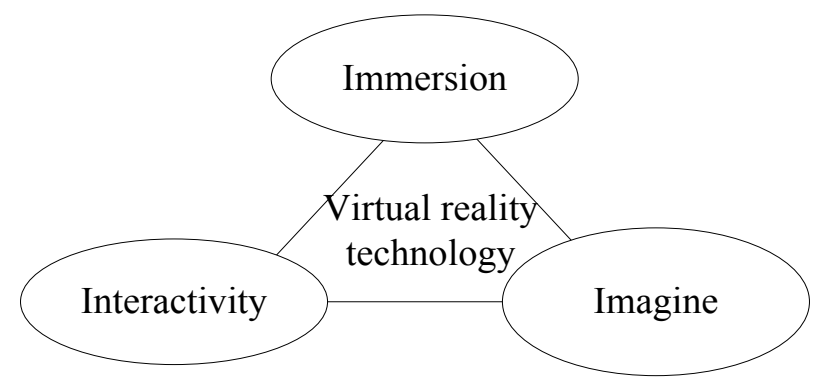

Fig. 3. VR technology 3I map

VRML. VRML is a modeling language and one of the core technologies for developing VR technology. VRML modeling language is better than other software in providing the users with better VR world, 3D scene and dynamic interactions [8]. It's requirement for system configuration is low with supporting for Zip compression format.

VRML files include two major parts: scene description and dynamic interaction. There is file header, scene graph structure, event structure, perceptron and distributed scene, display and interaction [9] and other functions. Figure 4 shows how VRML works. Designers use the relevant design software to design the corresponding scenarios and construct VRML files. When users need them, they can click and browse on the client side to finally achieve clients' distance access and interaction.

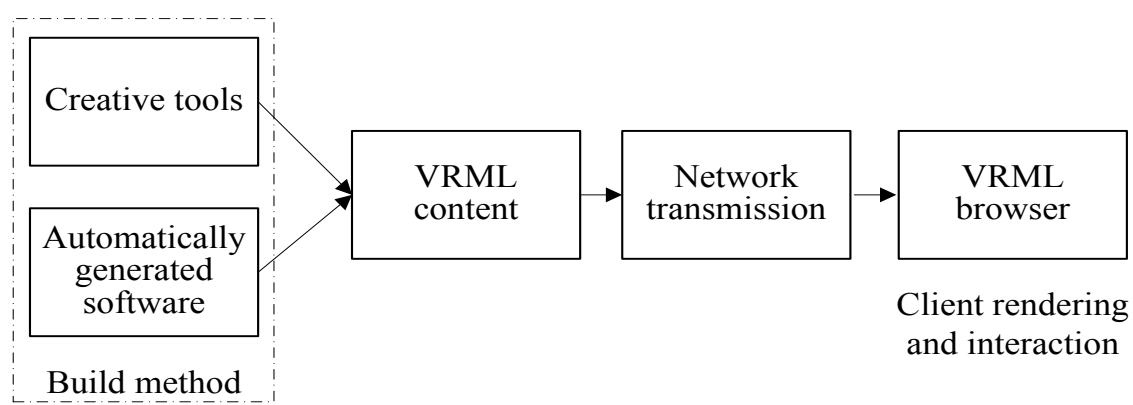

Fig. 4. How VRML works

\subsection{Virtual Experiment and Virtual Experiment Teaching}

At present there is no uniform definition of virtual experiment, in simple words, it 
uses computer, VR and other technologies to provide a simulation experiment environment and scenario (Virtual Lab), and a computer simulation experiment which can cultivate and practice the students' practical abilities [10]. According to the current level of technological development, virtual experiment can be achieved by four types of experiments: demonstration, distance control, simulation and emulation. Figure 5 shows the working principle of virtual laboratory.

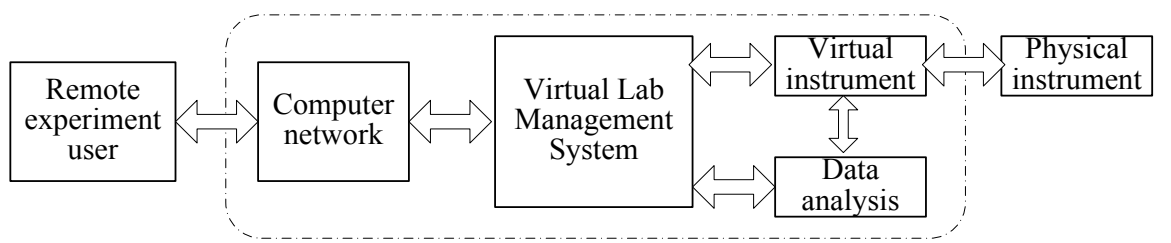

Fig. 5. Virtual laboratory working principle diagram

Virtual experiment teaching is an important part of computer distance teaching. It uses advanced technology to provide students with long-distance experimental teaching resources and creates a brand-new teaching method to improve the function of distance learning [11], So that students can fully exercise their practical ability, grasp basic theoretical knowledge solidly thus improving the teaching quality and promote the smooth development of distance teaching.

\section{VR technology-based computer distance virtual experiment teaching application}

The survey found that many courses are of great practicality and operability, but both the traditional teaching mode and the computer distance teaching mode can only explain the relevant principles and operations through the text, pictures and video explanations. Even though there are experimental courses in actual teaching classes, still there are few opportunities for students to actually practice hands-on activities due to experimental costs, teaching practice and other reasons, thus causing sever disjoint [12] in the theory and the practice. In computer distance teaching, learners would be in more lack in practice opportunities, and cannot achieve the desired teaching effect. In this case, successful construction of a virtual laboratory has great significance in achieving computer distance virtual experiment teaching.

In this paper, taking the course Computer Assembly and Maintenance as an example, a virtual computer assembly experiment platform is established to realize the computer distance virtual experiment teaching based on VR technology.

\subsection{Design of virtual computer assembly experiment}

Virtual experiment teaching design. To better achieve final teaching effect, we first divide the teaching goals and related experimental knowledge points of the course Computer Assembly and Maintenance, and then according to the division, we 
design three laboratory platforms, Figure 6 shows the function structure of the three platforms [13].

1. Computer peripheral lab: The main function is three-dimensional display and knowledge learning

2. Computer composition principle lab: The main function is installation instruction, installation demonstration, hands-on practice.

3. Computer composition principle lab: The main function is connection operation, data transmission, access verification and functional verification.

Design of main function modules. Based on the teaching design mentioned above, the virtual experiment teaching platform is divided into seven functional modules [14], as shown in Figure 5.

1. System homepage: simulate the real campus teaching scene, set up experimental teaching buildings, learners can use 3D avatars to truly experience the existence of the learning environment.

2. System Introduction: briefly introduce the function and use of the experimental teaching platform.

3. Basics: a learning resource that provides learners with basic knowledge through teaching resources such as texts, pictures and videos.

4. Virtual platform: 1) The computer peripheral lab provides the learners with computer equipment of different periods. The students can observe and study by clicking on the corresponding equipment, and also can learn the relevant knowledge of the equipment. 2) Computer assembly lab, through this lab, you can learn different types of computer hardware devices, click on the corresponding interface for different observation and study, you can click on the corresponding hardware and equipment, it will pop up the corresponding name and function description, you can rotate the view to conduct multi-angle observation, also you can experience immersive computer assembly operation by dragging the mouse and compare your operation with the right operation in the video to analyze your own problems.

5. Exchange Platform: Learners can exchange and discuss their studies through the message board of the exchange platform to promote communication and learning.

6. Use guide: to provide learners with relevant teaching resources and download connection of the plug-ins which are required by the platform.

7. Expand knowledge: this module provides students with deep learning and understanding of the relevant experimental knowledge. 


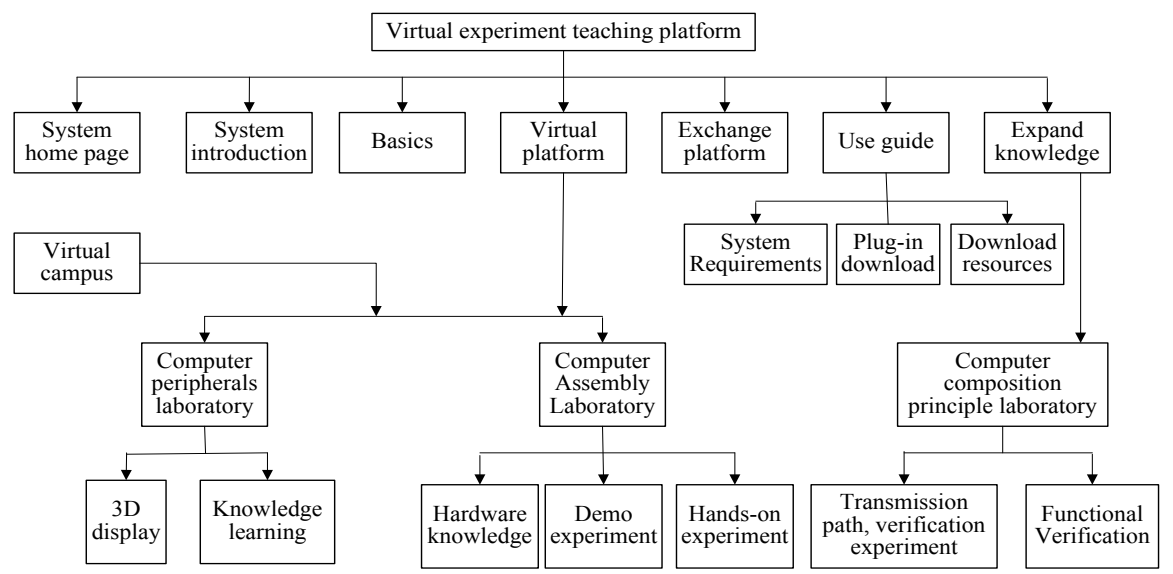

Fig. 6. System function block diagram

Design of virtual experiment teaching learning mode. According to above design of the virtual experiment teaching platform, this paper summarizes a suitable virtual experiment teaching learning mode for distance learners [15]. As shown in Figure 7, after entering the virtual scenario, the learners choose target experiment questions and scenes for themselves and then study by themselves. After their study, they can use the exchange platform to discuss their learning content with other learners to enhance the learning effect. After the reflection of their own problems, they can re-learn the relevant knowledge and deepen the impression.

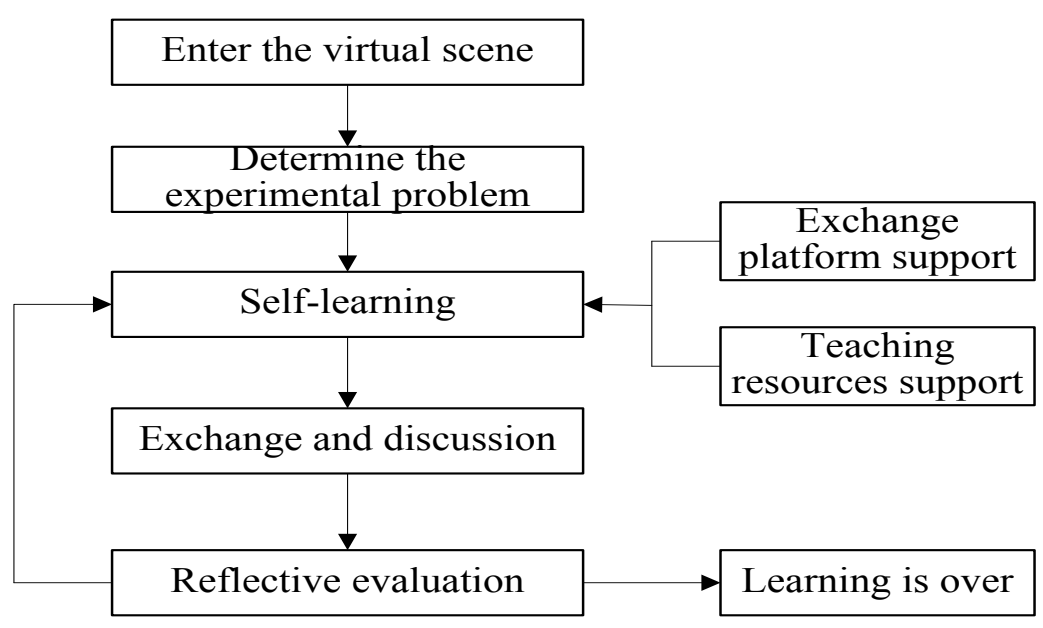

Fig. 7. Computer distance teaching virtual experiment teaching learning mode

\subsection{Realization of virtual computer assembly experiment}

The development of the virtual experiment includes the five processes: the material 
shooting of virtual environment and equipment; the construction of virtual experiment model; the realization of virtual experiment dynamic interaction; the optimization of VRML files, and the system platform integration [16]. This paper describes only a few of these key steps.

Virtual experiment modeling. Virtual experiment modeling can be divided into two kinds: simple objects modeling and complex objects modeling. In simple objects modeling, the modeling language is VRML, which is the core of VR technology. VRML describes the appearance of the entity using appearance attributes, location attributes and interaction attributes of the entity objects. Figure 8 shows the VRML programming interface, and Figure 9 shows the hard disk model directly built by the VRML language. For modeling of complex objects, it requires visual editing. In this paper, we use a more familiar 3DSMax to conduct modeling construction of complex scenes. Figure 10 shows the model design sketch of computer case through 3DSMax and its accompanied VRML plug-ins. To better satisfy user needs, usually we also need to optimize VRML files and models to achieve the goals of reducing file size and improving the performance.

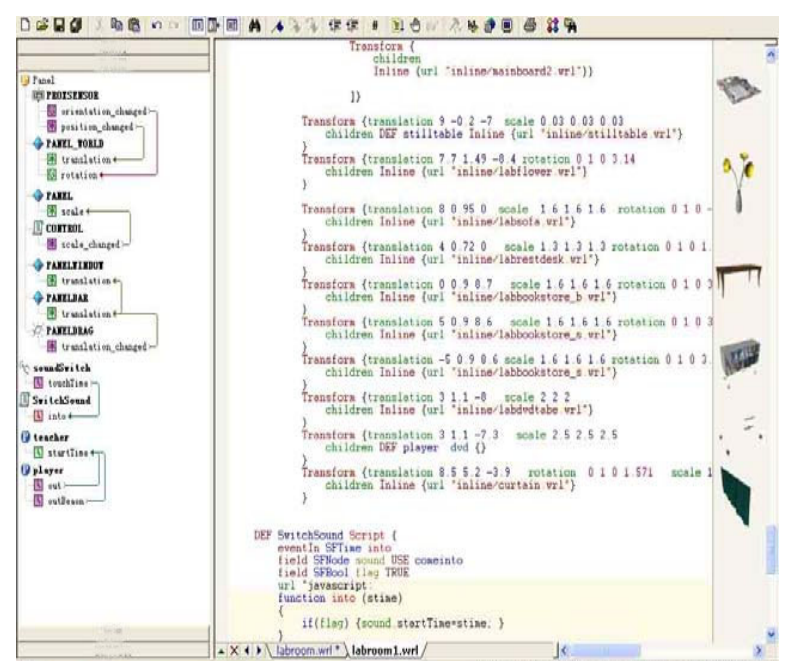

Fig. 8. VRML language programming interface 


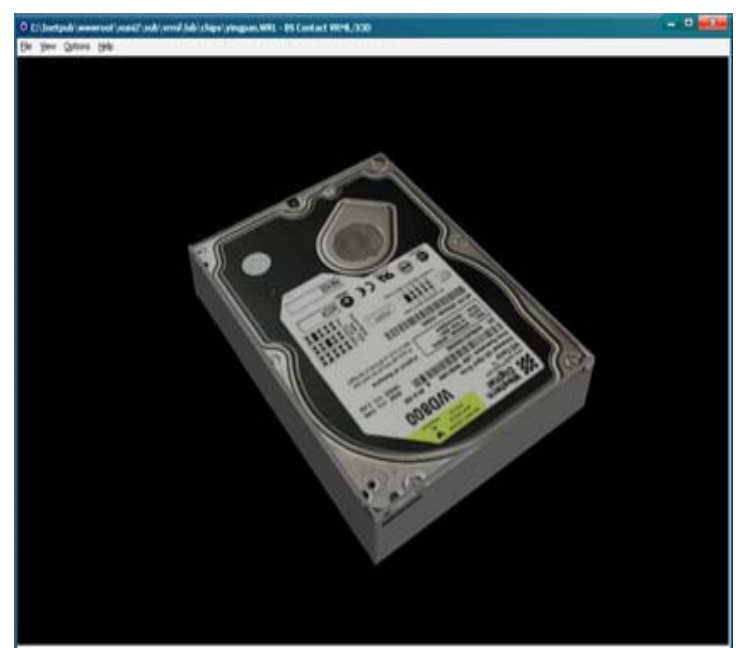

Fig. 9. Hard disk model built by VRML

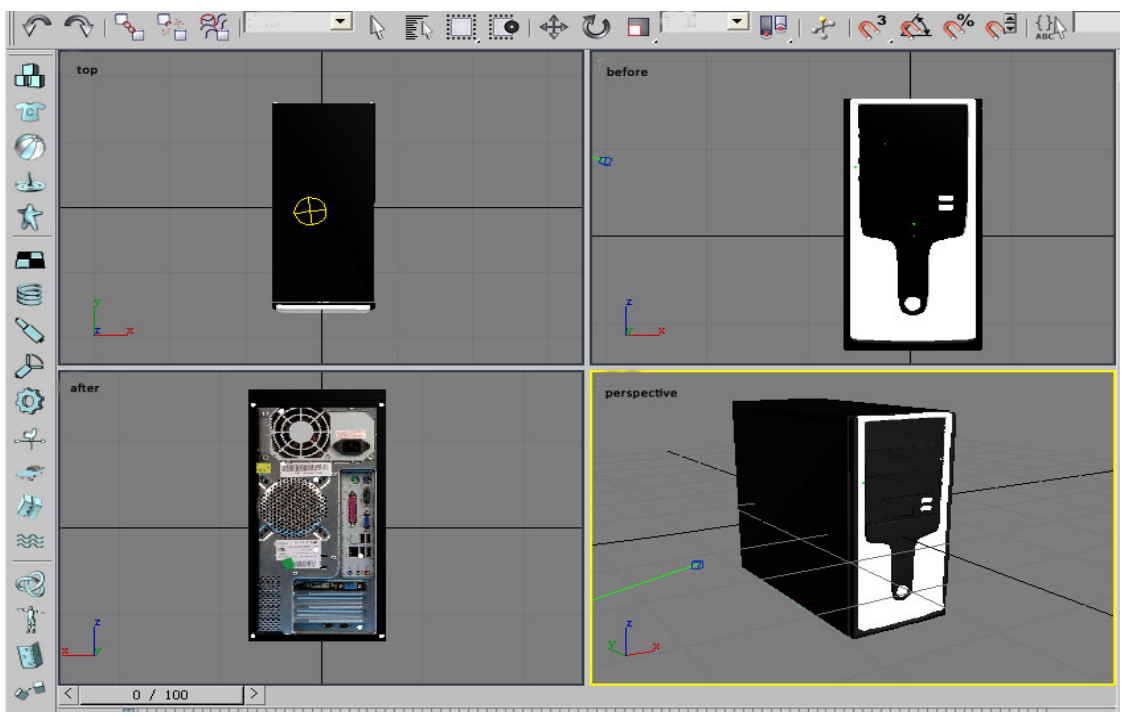

Fig. 10. Computer case model built with 3DSMax

The realization of interactive functions. The interactive function is to enable learners to "immerse" in the virtual environment, truly experience the movement, rotation and control of each study entity, so that learners have a real sense of participation, therefore, this paper uses VRML's expansion node Layer2D to achieve the button function and facilitate the realization of functions such as rotate and move in the learning interface. At the same time, the paper makes use of the static interactive functions of VRML and uses JavaScript and other related software to program and ultimately achieve the interactive functions such as select, move, rotate, and computer 
assembly experiments, Figure 11 shows the result of computer assembly simulation experiment completed by computer distance experiment.

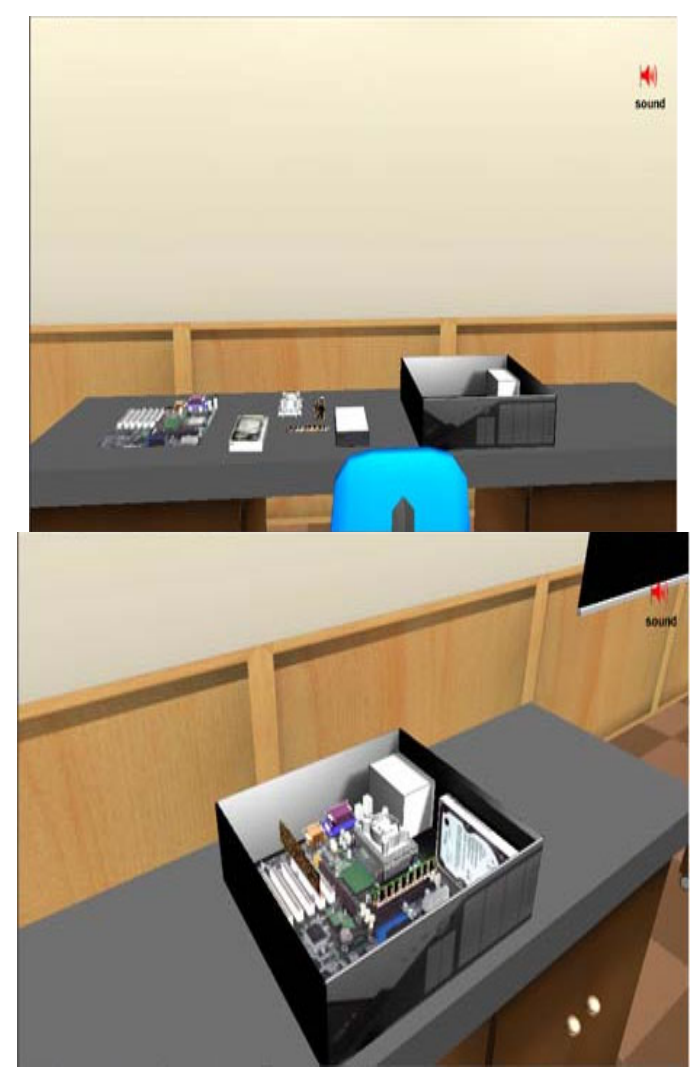

Fig. 11. Computer assembly experiment results

\section{Conclusion}

With the development of computer and VR technology, computer distance virtual experiment teaching will become one of the important teaching modes of computer distance teaching. This paper conducts research on the VR technology-based computer distance experiment teaching application and obtains following conclusions:

1. By summarizing and comparing the development of virtual experiment at home and abroad, the shortcomings of current virtual experiments are concluded.

2. Aiming at the problems of poor interactive function and less theoretical research in current computer distance virtual experiment teaching, this paper proposes a computer distance virtual experiment teaching mode based on VR technology.

3. Taking the computer assembly experiment as an example, the teaching model proposed in this paper has been designed in detail in the aspects of function module 
and learning mode. The realization of the computer assembly experiment shows that the model can realize the computer distance virtual experiment teaching, it verifies the feasibility of this teaching mode and has important practical significance for enriching and perfecting the computer distance teaching.

\section{References}

[1] Traphagan, T.W., Chang, H.M., Chang, H.M., Wattanawaha, B., Lee, H., Mayrath, M.C., et al. (2010). Cognitive, social and teaching presence in a virtual world and a text chat. Computers and Education, 55(3): 923-936. https://doi.org/10.1016/j.compedu.2010.04.003

[2] Brenton, H., Hernandez, J., Bello, F., Strutton, P., Purkayastha, S., Firth, T., et al. (2007). Using multimedia and web3d to enhance anatomy teaching. Computers and Education, 49(1): 32-53. https://doi.org/10.1016/j.compedu.2005.06.005

[3] Le, Q.T., Pedro, A., Chan, S.P. (2015). A social virtual reality based construction safety education system for experiential learning. Journal of Intelligent \& Robotic Systems, 79(3-4): 487-506. https://doi.org/10.1007/s10846-014-0112-z

[4] Hamrick, I., Hamrick, I. (2013). Virtual reality computer simulated home visit: teaching home safety. Journal of the American Medical Directors Association, 14(3): B12-B12. https://doi.org/10.1016/j.jamda.2012.12.033

[5] Ramasundaram, V., Grunwald, S., Mangeot, A., Comerford, N.B., Bliss, C.M. (2005). Development of an environmental virtual field laboratory. Computers \& Education, 45(1): 21-34. https://doi.org/10.1016/j.compedu.2004.03.002

[6] Yee, N. (2008). The use of immersive virtual reality in the learning sciences: Digital transformations of teachers, students, and social context. Journal of the Learning Sciences, 17(1): 102-141. https://doi.org/10.1080/10508400701793141

[7] Yellowlees, P.M., Cook, J.N. (2006). Education about hallucinations using an internet virtual reality system: A qualitative survey. Academic Psychiatry, 30(6): 534-530. https://doi.org/10.1176/appi.ap.30.6.534

[8] Chen, C.J. (2006). The design, development and evaluation of a virtual reality based learning environment. Australasian Journal of Educational Technology, 22(1): 39-63. https://doi.org/10.14742/ajet.1306

[9] Fowler, C. (2015). Virtual reality and learning: where is the pedagogy?. British Journal of Educational Technology, 46(2): 412-422. https://doi.org/10.1111/bjet.12135

[10] Sun, H.M., Cheng, W.L. (2009). The input-interface of webcam applied in $3 \mathrm{~d}$ virtual reality systems. Computers \& Education, 53(4): 1231-1240. DOI: 10.1016/j.compedu.2009.06.006 https://doi.org/10.1016/j.compedu.2009.06.006

[11] Dodd, B.J., Antonenko, P.D. (2012). Use of signaling to integrate desktop virtual reality and online learning management systems. Computers \& Education, 59(4): 1099-1108. https://doi.org/10.1016/j.compedu.2012.05.016

[12] Chen, C.J., Teh, C.S. (2013). Enhancing an instructional design model for virtual reality-based learning. Australasian Journal of Educational Technology, 29(5): 699-716. https://doi.org/10.14742/ajet.247

[13] Spaulding, S. (2002). Distance education, broadcast media, virtual reality, and cyberspace: is the future passing us by?. Comparative Education Review, 46(1): 119-130. https://doi.org/10.2307/3542024

[14] Keskitalo, T. (2012). Students' expectations of the learning process in virtual reality and simulation-based learning environments. Australasian Journal of Educational Technology, 28(5): 841-856. https://doi.org/10.14742/ajet.820 
[15] Huang, H.M., Rauch, U., Liaw, S.S. (2010). Investigating learners' attitudes toward virtual reality learning environments: based on a constructivist approach. Computers \& Education, 55(3): 1171-1182. https://doi.org/10.1016/j.compedu.2010.05.014

[16] Ai-Lim Lee, E., Wong, K.W., Fung, C.C. (2010). How does desktop virtual reality enhance learning outcomes? a structural equation modeling approach. Computers \& Education, 55(4): 1424-1442. https://doi.org/10.1016/j.compedu.2010.06.006

\section{Author}

Fengxu Wang, male. He was born in Liaocheng City on October 11th, 1978. He is a Lab technician with master degree. Now, he is employed in Liaocheng University, works on computer laboratory management and software program research.

Article submitted 20 February 2018. Final acceptance 25 March 2018. Final version published as submitted by the author. 